\title{
Subtype distribution of lymphomas in Southwest China: Analysis of 6,382 cases using WHO classification in a single institution
}

\author{
Qun-Pei Yang, Wen-Yan Zhang, Jian-Bo Yu, Sha Zhao, Huan Xu, Wei-Ya Wang, Cheng-Feng Bi, Zhuo Zuo, \\ Xiao-Qing Wang, Juan Huang, Lin Dai and Wei-Ping Liu*
}

\begin{abstract}
Background: The subtype distribution of lymphoid neoplasms in Southwest China was analyzed according to WHO classifications. This study aims to analyze subtype distribution of lymphomas in southwest China.

Methods: Lymphoid neoplasms diagnosed within 9 years in a single institution in Southwest China were analyzed according to the WHO classification.

Results: From January 2000 to December 2008, a total number of 6,382 patients with lymphoma were established, of which mature B-cell neoplasms accounted for 56\%, mature T- and NK-cell neoplasms occupied 26\%, and precursor lymphoid neoplasms and Hodgkin lymphomas were $5 \%$ and $13 \%$, respectively. Mixed cellularity (76\%) was the major subtype of classical Hodgkin lymphoma; and the bimodal age distribution was not observed. The top six subtypes of non-Hodgkin lymphoma were as follows: diffuse large B-cell lymphoma, extranodal NK/T-cell lymphoma, nasal type, extranodal marginal zone lymphoma of mucosa associated lymphoid tissue, follicular lymphoma, precursor lymphoid neoplasms, and chronic lymphocytic leukemia/small lymphocytic lymphoma. Extranodal lymphomas comprised about half of all cases, and most frequently involved Waldeyer's ring, gastrointestinal tract, sinonasal region and skin.

Conclusions: The lymphoid neoplasms of Southwest China displayed some epidemiologic features similar to those reported in literature from western and Asian countries, as well as other regions of China, whereas some subtypes showed distinct features. The high frequency of mature T/NK cell neoplasms and extranodal lymphomas, especially for extranodal NKT-cell lymphoma, nasal type, is the most outstanding characteristic of this series.
\end{abstract}

Keywords: Distribution, Lymphoma, Subtype, WHO classification

\section{Background}

Lymphoid neoplasms are a diverse group of malignancy that originate from either $\mathrm{B}, \mathrm{T}$ or NK cell, representing about $4 \%$ of the new cases of cancer diagnosed in China each year, making them the ninth most common cancer and the tenth leading cause of cancer death [1]. Previous epidemiologic studies have shown remarkable differences in the distribution of lymphoma subtypes between Asian and western populations [2-4]. However, the possible reasons of geographic differences in the spectrum of lymphoma remain unknown, mainly because the

\footnotetext{
* Correspondence: liuweiping2001@vip.sina.com

Department of Pathology, West China Hospital of Sichuan University,
} Chengdu, China etiology of lymphoma is largely unknown, even though some risk factors have been documented recently, including genetic factors, abnormality of immunity, individual susceptibilities, lifestyles, environmental exposures, as well as various kinds of infections caused by bacteria, viruses, mycoplasma and chlamydia [5].

Major progression has been made in understanding the pathobiology of these diseases in the last two decades, leading to the development of the internationally adopted WHO classification system and its updated version $[5,6]$. From then on, many studies on lymphoma incidence patterns or distributions were reported all over the world. However, research on distribution of lymphoma in Mainland China was still limited, and the 
case number was also small. In the current study, 6,382 consecutive patients diagnosed with lymphoid neoplasms according to WHO classification in the last nine years were reviewed and analyzed. The purpose was to estimate the subtype distribution of lymphomas and major clinical features and to compare the data of ours with those reported in the literature.

\section{Patients and methods}

The computerized database of all patients at the Department of Pathology, West China Hospital of Sichuan University was searched to identify patients with a diagnosis of lymphoma, excluding myeloid neoplasms and plasma cell myeloma/plasmacytoma. Cases in which the diagnoses of lymphoma were based on bone marrow biopsy alone and cases with inadequate materials were also excluded from this study. From January 2000 to December 2008, a total number of 6,382 cases diagnosed definitely with lymphoma were included. Clinical information including demographics (age, gender) and initial site involvement was collected from the submission of pathological samples and application tables for consultants.

Hematoxylin-eosin-stained sections were examined histopathologically. For immunohistochemical staining of paraffin-embedded sections, antibodies selected included CD3, CD3e, CD4, CD5, CD8, CD10, CD15, CD20, CD21, CD23, CD30, CD43, CD45RO, CD56, CD79 $\alpha$, CD99, ALK-1 (anaplastic large cell lymphoma kinase-1), EMA (epithelial membrane antigen), cyclin D1, BCL-2, BCL-6, Mum1, $\kappa$ and $\lambda$ light chain, Ki-67, Granzyme B, TIA-1 (T-cell intracytoplasmic antigen-1), TdT, EBV. In situ hybridization for EBV-encoded small RNA (EBER) and IgH and/or TCR gene rearrangement detected by polymerase chain reaction were performed when the diagnosis was not clear from the histopathologic and immunophenotypic evaluation. All cases were diagnosed and classified in accordance with the criteria of WHO classification of Tumors of Haematopoietic and Lymphoid Tissue (2001). The protocol of this study was approved by the Institutional Review Board or ethical committee of West China Hospital of Sichuan University. Informed consent for the collection of medical information for in patients, out patients and consultants was obtained at their first visit.

\section{Results}

A total number of 6,382 lymphomas were included in this study, in which 3,160 were consultant cases (49.5\%) from all regions of southwestern China. All of the subtypes described in WHO classifications were presented but hairy cell leukemia, intravascular large B-cell lymphoma, primary effusion lymphoma, T-cell large granular lymphocytic leukemia, adult T-cell leukemia/ lymphoma (ATLL) and both B- and T-cell prolymphocytic leukemia.

The major clinicopathologic characteristics of this series are shown in Table 1. Of the 6,382 lymphomas, 833 were Hodgkin lymphomas (HL) and 5,549 were nonHodgkin lymphomas (NHL). Classical HL (CHL) accounted for $95.8 \%$ of HL. Three quarters were mixed cellularity (MC-CHL), and $18 \%$ were nodular sclerosis (NS-CHL). In all cases of 5,549 NHLs, $64.4 \%$ of them were mature B-cell neoplasms (3,571 cases). The most common subtype was diffuse large B-cell lymphoma (DLBCL), followed by extranodal marginal zone B-cell lymphoma of mucosa-associated lymphoid tissue (MALT lymphoma), follicular lymphoma (FL), chronic lymphocytic leukemia/small lymphocytic lymphoma (CLL/SLL), mantle cell lymphoma (MCL), and Burkitt lymphoma. In addition, $30.2 \%$ of NHLs were mature Tand NK-cell neoplasms (1,677 cases). The most common subtype was extranodal NK/T-cell lymphoma, nasal type (ENKTCL), followed by peripheral T-cell lymphoma, not otherwise specified (PTCL, NOS), anaplastic large cell lymphoma (ALCL), angioimmunoblastic T-cell lymphoma (AITL), subcutaneous panniculitis-like T-cell lymphoma (SPTCL) and primary cutaneous CD30 positive lymphoproliferative disorders (PCCD30LD). Furthermore, $5.4 \%$ of NHLs were lymphoblastic leukemia/lymphoma (LBL, 301 cases), most of which were Tlymphoblastic.

Most subtypes of lymphomas were prone to involve males. Striking male predominance was observed for MCL and lymphocyte rich CHL (LR-CHL) with the M/F ratio of 3.1 and 4.8, respectively. For male patients, the top five common subtypes were as follows: DLBCL, ENKTCL, MC-CHL, FL and LBL; whereas for female patients, they were DLBCL, ENKTCL, MC-CHL, MALT and FL.

Age and sex distribution by subtypes of lymphoma is shown in Figure 1. The most common pediatric (age younger than $15 \mathrm{yr}$ ) lymphoma was MC-CHL, followed by LBL, ALCL, Burkitt, DLBCL. For adolescents and young adults (age $15 \mathrm{yr}$ to $24 \mathrm{yr}$ ), MC-CHL was still the leading subtype, followed by ENKTCL, DLBCL, and LBL. For adults, DLBCL was the most common subtype, followed by ENKTCL, MC-CHL, FL, and MALT. For the elderly (aged older than $64 \mathrm{yr}$ ), DLBCL comprised approximately half of all lymphomas, followed by ENKTCL, MALT, CLL/SLL, and AITL.

In this study, extranodal lymphoma refers to lymphoma arising primarily from sites other than lymph nodes, spleen, bone marrow, or mediastinum (lymph nodes and thymus). Comparison of subtype distribution between extranodal and nodal lymphomas is shown in Figure 2. Approximately $53.5 \%$ of all NHL presented in extranodal sites at diagnosis. Figure 3 
Table 1 Subtypes of lymphomas $(n=6,382)$

\begin{tabular}{|c|c|c|c|c|c|c|c|c|c|}
\hline \multirow[b]{2}{*}{ Subtype } & \multirow[b]{2}{*}{ No. } & \multicolumn{2}{|c|}{ Age (year) } & \multicolumn{3}{|c|}{ Sex } & \multicolumn{3}{|c|}{ Site } \\
\hline & & Median & Range & Male & Female & $M: F$ & Nodal & Extranodal & N/E \\
\hline DLBCL & 2288 & 55 & $3-93$ & 1359 & 929 & 1.5 & 1027 & 1261 & 0.81 \\
\hline ENKTCL & 949 & 41 & $1-82$ & 668 & 281 & 2.4 & 32 & 917 & 0.03 \\
\hline MALT & 350 & 56 & $16-86$ & 183 & 167 & 1.1 & 20 & 330 & 0.06 \\
\hline $\mathrm{FL}$ & 327 & 54 & $23-83$ & 213 & 114 & 1.9 & 292 & 35 & 8.34 \\
\hline LBL & 301 & 19 & $1-71$ & 211 & 90 & 2.3 & 253 & 48 & 5.27 \\
\hline CLL/SLL & 256 & 60 & $22-88$ & 180 & 76 & 2.4 & 228 & 28 & 8.14 \\
\hline PTCL, NOS & 221 & 55 & $12-90$ & 148 & 73 & 2 & 152 & 69 & 2.2 \\
\hline $\mathrm{ALCL}$ & 196 & 27.5 & $4-71$ & 118 & 78 & 1.5 & 151 & 45 & 3.36 \\
\hline AITL & 185 & 61 & $20-86$ & 124 & 61 & 2 & 185 & 0 & - \\
\hline MCL & 175 & 61 & $20-79$ & 132 & 43 & 3.1 & 126 & 49 & 2.57 \\
\hline Burkitt & 106 & 15.5 & $2-69$ & 78 & 28 & 2.8 & 49 & 57 & 0.86 \\
\hline SPTCL & 54 & 33 & $4-68$ & 25 & 29 & 0.9 & 0 & 54 & 0 \\
\hline LPL & 44 & 61 & $30-82$ & 25 & 19 & 1.3 & 34 & 10 & 3.4 \\
\hline PCCD30LD & 37 & 37 & $2-78$ & 18 & 19 & 0.9 & 0 & 37 & - \\
\hline SMZBCL & 20 & 61.5 & $15-76$ & 10 & 10 & 1 & 20 & 0 & - \\
\hline HSTCL & 14 & 25 & $11-46$ & 9 & 5 & 1.8 & 5 & 9 & 0.56 \\
\hline MF/SS & 14 & 52.5 & $31-80$ & 8 & 6 & 1.3 & 0 & 14 & - \\
\hline ETCL & 7 & 29 & $17-42$ & 5 & 2 & 2.5 & 0 & 7 & - \\
\hline NMZBCL & 5 & 64 & $52-80$ & 3 & 2 & 1.5 & 5 & 0 & - \\
\hline $\mathrm{MC}-\mathrm{CHL}$ & 606 & 31 & $3-89$ & 433 & 173 & 2.5 & 597 & 9 & 66.3 \\
\hline NS-CHL & 145 & 29 & $3-76$ & 75 & 70 & 1.1 & 139 & 6 & 23.2 \\
\hline LR-CHL & 35 & 30 & $4-64$ & 29 & 6 & 4.8 & 35 & 0 & - \\
\hline LD-CHL & 12 & 53 & 19-82 & 6 & 6 & 1 & 12 & 0 & - \\
\hline NLPHL & 35 & 36 & 8-74 & 25 & 10 & 2.5 & 34 & 1 & 34 \\
\hline Total & 6382 & 50 & $1-93$ & 4085 & 2297 & 1.8 & 3396 & 2986 & 1.1 \\
\hline
\end{tabular}

DLBCL, diffuse large B-cell lymphoma; ENKTCL, extranodal NK/T-cell lymphoma, nasal type; MALT, extranodal marginal zone lymphoma of mucosa associated lymphoid tissue; FL, follicular lymphoma; LBL, lymphoblastic leukemia/lymphoma; CLL/SLL, chronic lymphocytic leukemia/small lymphocytic lymphoma; PTCL, NOS, peripheral T-cell lymphoma, not otherwise specified; ALCL, anaplastic large cell lymphoma; AITL, angioimmunoblastic T-cell lymphoma; MCL, mantle cell lymphoma; Burkitt, Burkitt lymphoma; SPTCL, subcutaneous panniculitis-like T-cell lymphoma; LPL, lymphoplasmacytic lymphoma; PCCD30LD, primary cutaneous CD30 positive lymphoproliferative disorders; SMZBCL, splenic marginal zone B-cell lymphoma; HSTCL, hepatosplenic T-cell lymphoma; MF/SS, mycosis fungoides/ Sezary syndrome; ETCL, enteropathy-associated T-cell lymphoma; NMZBCL, nodal marginal zone B-cell lymphoma; MC-CHL, mixed cellularity classical Hodgkin lymphoma; NS-CHL, nodular sclerosis classical Hodgkin lymphoma; LR-CHL, lymphocyte-rich classical Hodgkin lymphoma; LD-CHL, lymphocyte-depleted classical Hodgkin lymphoma; NLPHL, nodular lymphocyte predominant Hodgkin lymphoma.

shows the anatomical sites most commonly involved by extranodal lymphomas. Lymphomas of Waldeyer's ring, gastrointestinal tract, sinonasal regions and skin represented most of the extranodal lymphomas. DLBCL was found to be the most common subtype of both extranodal and nodal lymphomas, followed by ENKTCL and FL, respectively. Concerning the distribution of histologic subtypes, those involving in particular extranodal sites, DLBCL and ENKTCL made up the majority of NHL in Waldeyer's ring; DLBCL and MALT composed over $80 \%$ of all lymphomas in the gastrointestinal tract; ENKTCL primarily represented the sinonasal lymphomas. For skin lymphomas, except for MF, PCCD30LPD, SPTCL and ENKTCL were relatively common. For nodal-based lymphomas, cervical, inguinal, axillary, and supraclavicular lymph nodes were frequently involved. About 76\% of nodal-based lymphomas were NHLs, in which the top eight subtypes were as follows: DLBCL, FL, LBL, CLL/SLL, AITL, PTCL, NOS, ALCL, and MCL.

\section{Discussion}

Epidemiologic studies suggest that distribution of lymphoma subtypes differs strikingly by geographic variations [2]. But there is limited information on this research in Mainland China. Up to now, this report demonstrates the largest comprehensive descriptive study of subtype distribution of lymphomas classified by the WHO criteria in a single institution from China.

According to the latest SEER data [7], HL made up $11 \%$ of all lymphomas. In our observation, this figure was $13 \%$, similar to US and most of the reports from China but a little higher than Japan and South Korea [8-14]. As for subtypes, MC-CHL is the most common of HL, followed by NS-CHL in this series, whereas NS$\mathrm{CHL}$ is much more frequent than MC-CHL (70\% versus 


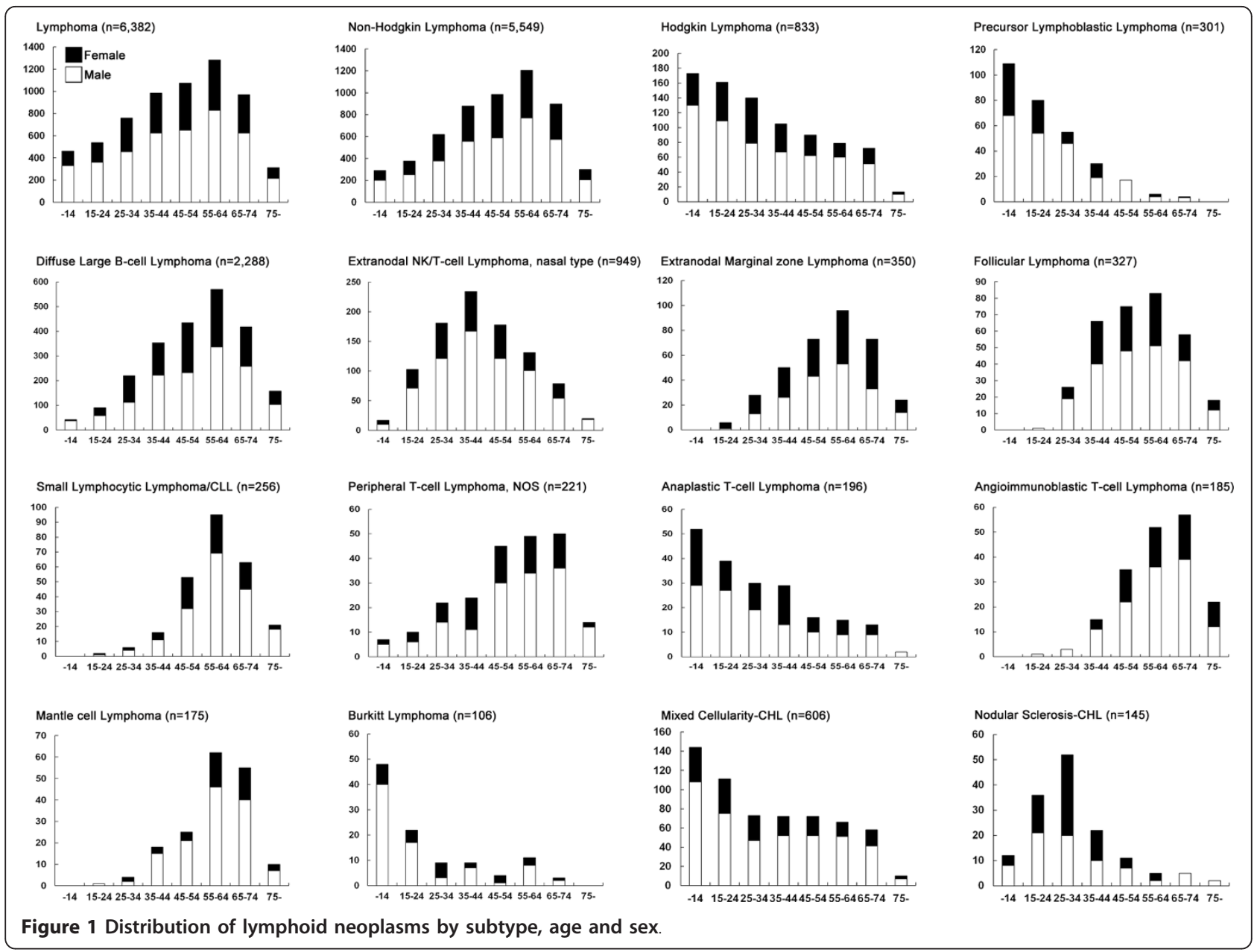

20 25\%) in Western countries [5,6,15]. MC-CHL has a strong association with EBV, and Armstrong et al [16] have proposed a three-disease model on the basis of age and EBV status. We have found that $73.3 \%$ of $\mathrm{MC}-\mathrm{CHL}$ had EBV, whereas only one-fifth of NS-CHL cases had EBV and EBV was negative in the remaining subtypes. Therefore, EBV-associated disease in childhood may contribute to the high frequency of $\mathrm{MC}-\mathrm{CHL}$ in the
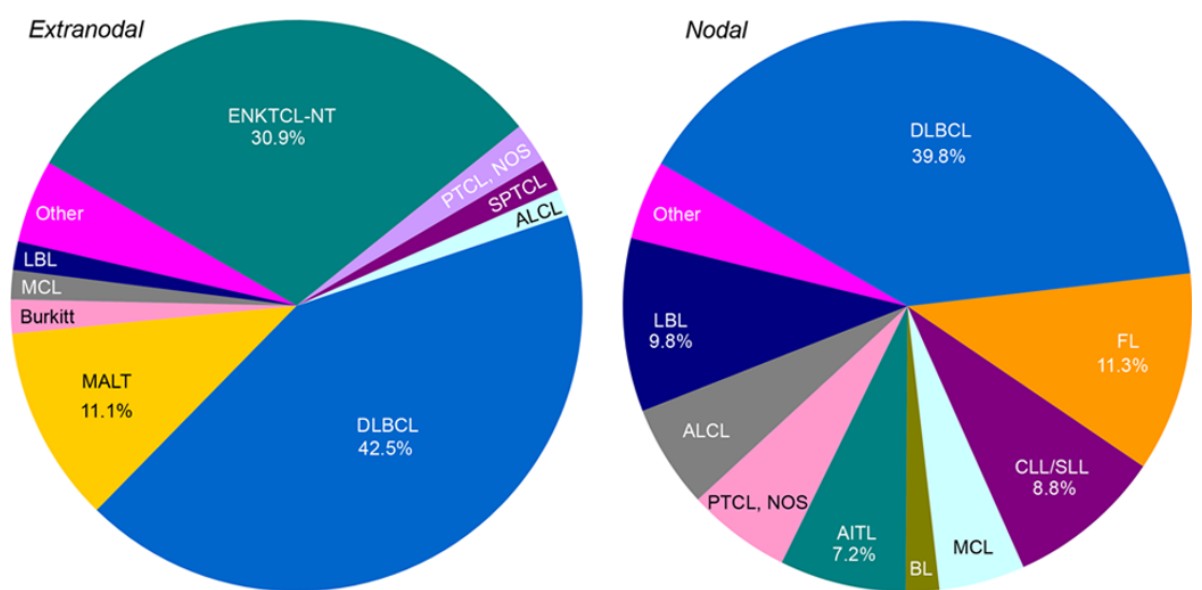

Figure 2 Distribution of histological subtypes in extranodal and nodal lymphoma. 


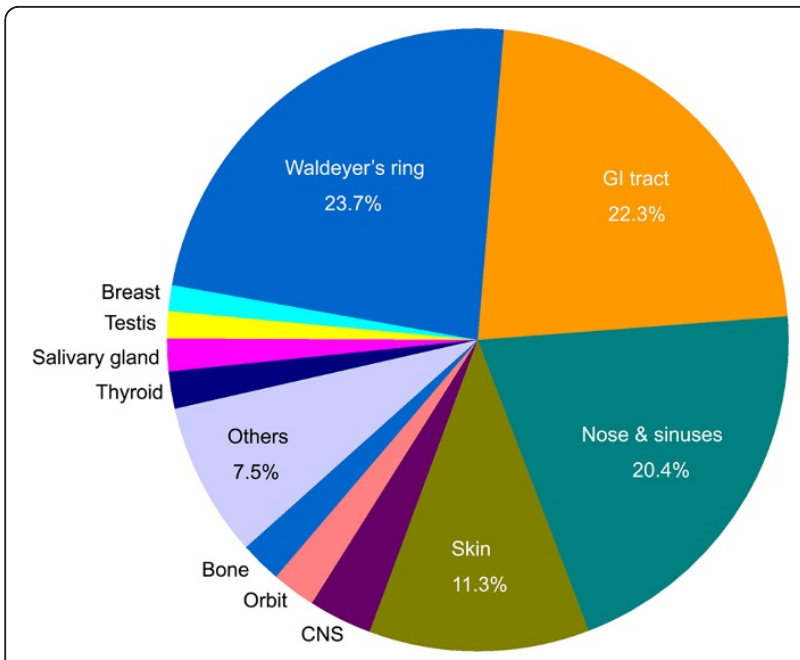

Figure 3 Extranodal sites involved in non-Hodgkin lymphoma. Waldeyer's ring includes tonsil, palate, nasopharynx, pharynx and base of tongue; $\mathrm{Gl}$ tract (gastrointestinal tract) includes stomach, small intestine and colon; Nose \& sinuses includes nasal cavity and paranasal sinuses; CNS, central nervous system.

current study. However, more evidence will be needed. Another difference is that HL shows a gradual decline in cases with age in this series, whereas a bimodal age curve (a peak at 15 35 years of age and a second peak in late life) is apparent in Europe and North America. Furthermore, report from Japan shows that a single peak age of HL was in the elderly [10]. Nakatsuka and Aozasa [17] have pointed out that the bimodal age curve might be formed by the different peak ages of the two main subtypes, MC-CHL (later years) and NS-CHL (young adults).

Comparison on the incidence of NHL between our findings and others is shown in additional file 1, table 1 . Similar to other reports, DLBCL was also the leading histological subtype, but the frequency of FL was lower than that of western countries, a phenomenon commonly seen in the Chinese population [18]. In China, DLBCL is still the most common subtype of B-cell lymphomas, but the second most common subtype varies a little from region to region [11-14,18-21]. Classification of DLBCL into prognostically distinct subtypes has progressed from gene expression profiles (GEP) in research to immunochemistry for a panel of markers which could be done routinely [22-26]. Based on Hans' algorithm [24], 79\% of the 364 cases of DLBCL in which CD10, BCL- 6 and Mum1 had been completely performed in this collection were categorized into nonGCB subtype, agreeing very well with the result of recent research for Chinese patients [27].

It is commonly thought that mature T/NK-cell neoplasms display higher rates on the Asian continent than others $[28,29]$. A recent large international retrospective study validated the geographic variations and showed the high frequency of ALCL, ALK-positive in North America, AITL and ETCL in Europe, ATLL in Japan and ENKTCL in Asian countries other than Japan [4]. In fact, the geographic variations also could be found across China; ENKTCL is the most common subtype of PTCL in Hong Kong and this group, whereas PTCL, NOS in all other parts [11-14,18-21,30]. Peripheral T/ NK-cell lymphomas comprised $30.2 \%$ of non-Hodgkin lymphomas in the current study, higher than other Asian reports using WHO classification $[8-14,18-21,30,31]$. This is likely due to the strikingly high percentage of ENKTCL in this series. Research has suggested that environmental factors including EBV infection as well as exposure to pesticides and chemical solvents were strongly associated with this disease $[32,33]$. Considering that Sichuan province is a main agricultural area in China, this may be explained. However, further research on this aspect should be done. In addition, the high proportion of consultant cases (38.4\%) may also contribute to the high percentage of ENKTCL.

As for age-specific incidence, the subtypes of pediatric (younger than 15-year old) lymphoma are limited, including CHL (mainly MC type), LBL, ALCL, Burkitt and DLBCL. This is in accordance with reports in the literature $[34,35]$. However, in any age group but pediatric, ENKTCL takes second place following DLBCL in this study. In addition, the median ages of most patients were about 10 years younger than that of Japanese and American patients $[10,15]$. The present findings may be due to an impressively increased and further increasing life expectancy and the high ratio of the aging population in developed countries [36].

The frequency of extranodal NHL varies in different parts of the world. Studies from Western countries have reported the occurrence of extranodal NHL as $24-48 \%$ of all NHL [37-40]. However, this figure is higher in Asia, for example, Pakistan (42\%), Kuwait (45\%), Japan (46.6\%), Korea (55\%), Thailand (58.7\%), and China (44.9\%-61.4\%)[8-14,18-21,41-43]. The fluctuating frequency of extranodal lymphomas may be caused by genetic and ethnic factors, as well as the diverse definition criteria. Additionally, extranodal NHL in this series most commonly involved Waldeyer's ring, whereas the GI tract is reported to be the most common site in the literature [37-39]. The relatively high frequency of ENKTCL which mainly involves the sinonasal region and Waldeyer's ring may contribute to this difference.

Considering that the patients, including consultation cases, were referred from all regions of southwest China, the results may represent the distribution of lymphoma subtypes in southwest China. Diagnoses made on the bone marrow were excluded because this research was 
focused on lymphomas, not leukemia. This may result in under-representation of CLL and MALT lymphoma. However, since these diagnoses were not just based on bone marrow biopsy, the influence was not considerable.

In conclusion, subtype distribution of lymphomas in the current study is demonstrated and compared with reports all over the world and inside China. No bimodal age distribution was observed in CHL, and the major subtype of CHL is mixed cellularity, not nodular sclerosis. A high percentage of extranodal lymphomas are presented, including a relatively high frequency of ENKTCL.

\section{Additional material}

Additional file 1: Subtype distribution of non-Hodgkin lymphoma across the world. Subtype distribution of non-Hodgkin lymphoma across the world

\section{Acknowledgements}

This work was supported by the National Natural Science Foundation of China (grant number 30971113, 30901690), the Ph.D. Programs Foundation of Ministry of Education of China (grant number 20070610141), the Research Fund for the Doctoral Program of Higher Education of China (grant number 200806101053), the Ministry of Health Industry Research Special Fund funded projects (grant number 200802011).

\section{Authors' contributions}

QPY participated in the design, analyses and data interpretation and drafted the manuscript. WYZ, JBY, SZ, HX, WYW, CFB, ZZ, XQW, JH, LD collected pathologic and clinical information and helped to draft the manuscript. WPL conceived of the study and participated in its design and analyses and helped to draft the manuscript. All authors read and approved the final manuscript.

\section{Competing interests}

The authors declare that they have no competing interests.

Received: 24 July 2011 Accepted: 22 August 2011

Published: 22 August 2011

\section{References}

1. Zhang SW, Lei ZL, Li GL, Zou XN, Zhao P, Chen WQ: A Report of Cancer Incidence and Mortality from 34 Cancer Registries in China, 2006. Zhong Guo Zhong Liu 2010, 19:356-365.

2. Anderson JR, Armitage JO, Weisenburger DD: Epidemiology of the nonHodgkin's lymphomas: distributions of the major subtypes differ by geographic locations. Non-Hodgkin's Lymphoma Classification Project. Ann Oncol 1998, 9:717-720.

3. Au WY, Gascoyne RD, Klasa RD, Connors JM, Gallagher RP, Le ND, Loong F, Law CK, Liang R: Incidence and spectrum of non-Hodgkin lymphoma in Chinese migrants to British Columbia. Br J Haematol 2005, 128:792-796.

4. Vose J, Armitage J, Weisenburger D: International peripheral T-cell and natural killer/T-cell lymphoma study: pathology findings and clinical outcomes. J Clin Oncol 2008, 26:4124-4130.

5. Jaffe ES, NL H, Stein H, Vardiman JW: WHO Classification: Pathology and Genetics of Tumors of Haematopoietic and Lymphoid Tissues Lyon: IARC; 2001.

6. Swerdlow SH, Campo E, Harris NL, Jaffe ES, Pileri SA, Stein H, Thiele J, Vardiman JW: WHO Classification: Pathology and Genetics of Tumors of Haematopoietic and Lymphoid Tissues Lyon: IARC; 2008.

7. Jemal A, Siegel R, Xu J, Ward E: Cancer Statistics, 2010. CA Cancer J Clin 2011, 60:277-300.
8. Yoon S, Suh C, Lee D, Chi H, Park C, Jang S, Shin H, Park B, Huh J: Distribution of lymphoid neoplasms in the Republic of Korea: Analysis of 5318 cases according to the World Health Organization classification. Am J Hematol 2010, 85:760-764.

9. Sukpanichnant S: Analysis of 1983 cases of malignant lymphoma in Thailand according to the World Health Organization classification. Hum Pathol 2004, 35:224-230.

10. Aoki R, Karube K, Sugita Y, Nomura Y, Shimizu K, Kimura Y, Hashikawa K, Suefuji N, Kikuchi M, Ohshima K: Distribution of malignant lymphoma in Japan: analysis of 2260 cases, 2001-2006. Pathol Int 2008, 58:174-182.

11. Lee MY, Tan TD, Feng AC, Liu MC: Clinicopathological analysis of 598 malignant lymphomas in Taiwan: seven-year experience in a single institution. Am J Hematol 2006, 81:568-575.

12. Chen $W$, Tsai W, Chao T: The clinicopathological analysis of 303 cases with malignant lymphoma classified according to the World Health Organization classification system in a single institute of Taiwan. Ann Hematol 2010, 89:553-562.

13. Gross SA, Zhu X, Bao L, Ryder J, Le A, Chen Y, Wang XQ, Irons RD: A prospective study of 728 cases of non-Hodgkin lymphoma from a single laboratory in Shanghai, China. Int J Hematol 2008, 88:165-173.

14. Wang J, Young L, Win W, Taylor CR: Distribution and ZAP-70 Expression of WHO Lymphoma Categories in Shanxi, China: A Review of 447 Cases Using a Tissue Microarray Technique. Appl Immunohisto M M 2005, 13:323-332.

15. Morton LM, Wang SS, Devesa SS, Hartge P, Weisenburger DD, Linet MS: Lymphoma incidence patterns by WHO subtype in the United States, 1992-2001. Blood 2006, 107:265-276.

16. Armstrong A, Alexander F, Cartwright R, Angus B, Krajewski A, Wright $D$, Brown I, Lee F, Kane E, Jarrett R: Epstein-Barr virus and Hodgkin's disease: further evidence for the three disease hypothesis. Leukemia 1998, 12:1272-1276.

17. Nakatsuka S, Aozasa K: Epidemiology and pathologic features of Hodgkin lymphoma. Int J Hematol 2006, 83:391-397.

18. Au WY, Ma SY, Chim CS, Choy C, Loong F, Lie AK, Lam CC, Leung AY, Tse E, Yau CC, et al: Clinicopathologic features and treatment outcome of mature T-cell and natural killer-cell lymphomas diagnosed according to the World Health Organization classification scheme: a single center experience of 10 years. Ann Oncol 2005, 16:206-214.

19. Xiao C, Su ZL, Wu QL, Hao HY, Fang JC, Xia ZJ, Guan ZC: Clinical and pathological reassessment of 493 cases of non-Hodgkin's lymphomas according to current WHO classification of lymphoid neoplasms. Zhong Hua Bing Li Xue Za Zhi 2005, 34:22-27.

20. Zhou LQ, Sun Y, Tan WY, Li T, Wang QL, Feng FY, Wang JW, Chu DT, Shi YK, Li YX, et al: The clinical and pathological analysis for 1125 cases with non-Hodgkin's lymphoma. Ai Zheng Jin Zhan 2006, 4:391-397.

21. Yang SE, Li X, Zhao B, Jia CD, Zhang GQ: The Clinical and Pathological Analysis of 1,012 Cases of Non-Hodgkins Lymphoma. Zhong Guo Zhong Liu Lin Chuang 2009, 36:1412-1415.

22. Alizadeh AA, Eisen MB, Davis RE, Ma C, Lossos IS, Rosenwald A, Boldrick JC, Sabet $H$, Tran T, Yu X, et al: Distinct types of diffuse large B-cell lymphoma identified by gene expression profiling. Nature 2000 403:503-511.

23. Rosenwald A, Wright G, Chan WC, Connors JM, Campo E, Fisher Rl, Gascoyne RD, Muller-Hermelink HK, Smeland EB, Giltnane JM, et al: The use of molecular profiling to predict survival after chemotherapy for diffuse large-B-cell lymphoma. N Engl J Med 2002, 346:1937-1947.

24. Hans C, Weisenburger D, Greiner T, Gascoyne R, Delabie J, Ott G, MullerHermelink H, Campo E, Braziel R, Jaffe E: Confirmation of the molecula classification of diffuse large B-cell lymphoma by immunohistochemistry using a tissue microarray. Blood 2004, 103:275-282.

25. Choi WWL, Weisenburger DD, Greiner TC, Piris MA, Banham AH, Delabie J, Braziel RM, Geng H, lqbal J, Lenz G, et al: A New Immunostain Algorithm Classifies Diffuse Large B-Cell Lymphoma into Molecular Subtypes with High Accuracy. Clin Cancer Res 2009, 15:5494-5502.

26. Meyer PN, Fu K, Greiner TC, Smith LM, Delabie J, Gascoyne RD, Ott G Rosenwald A, Braziel RM, Campo E, et al: Immunohistochemical Methods for Predicting Cell of Origin and Survival in Patients With Diffuse Large B-Cell Lymphoma Treated With Rituximab. J Clin Oncol 2011, 29:200-207.

27. Chen Y, Han T, Iqbal J, Irons R, Chan W, Zhu X, Fu K: Diffuse Large B-Cell Lymphoma in Chinese Patients: Immunophenotypic and Cytogenetic Analyses of 124 Cases. Am J Clin Pathol 2010, 133:305-313. 
28. The Non-Hodgkin's Lymphoma Classification Project: A clinical evaluation of the International Lymphoma Study Group classification of nonHodgkin's lymphoma. Blood 1997, 89:3909-3918.

29. Kwong YL, Anderson BO, Advani R, Kim WS, Levine AM, Lim ST: Management of T-cell and natural-killer-cell neoplasms in Asia: consensus statement from the Asian Oncology Summit 2009. Lancet Oncol 2009, 10:1093-1101.

30. Liang $Q$, Ye ZY, Su ZL, Lin HL, Shao CH, Lin SX, Rao HL, Mei KY, Zhao T, Liu YH, et al: Clinicopathologic study of 963 cases of mature T-cell and natural killer/T-cell lymphoma with respect to 2008 WHO classification of lymphoid neoplasms. Zhong Hua Bing Li Xue Za Zhi 2010, 39:291-295.

31. Ko OB, Lee DH, Kim SW, Lee JS, Kim S, Huh J, Suh C: Clinicopathologic characteristics of T-cell non-Hodgkin's lymphoma: a single institution experience. Korean J Intern Med 2009, 24:128-134.

32. Xu JX, Hoshida Y, Yang WI, Inohara H, Kubo T, Kim GE, Yoon JH, Kojya S, Bandoh N, Harabuchi Y, et al: Life-style and environmental factors in the development of nasal NK/T-cell lymphoma: a case-control study in East Asia. Int J Cancer 2006, 120:406-410.

33. Aozasa K, Takakuwa T, Hongyo T, Yang W-I: Nasal NK/T-cell lymphoma: epidemiology and pathogenesis. Int J Hematol 2008, 87:110-117.

34. Hochberg J, Waxman IM, Kelly KM, Morris E, Cairo MS: Adolescent nonHodgkin lymphoma and Hodgkin lymphoma: state of the science. $\mathrm{Br} J$ Haematol 2009, 144:24-40.

35. The Non-Hodgkin's Lymphoma Classification Project: Effect of age on the characteristics and clinical behavior of non-Hodgkin's lymphoma patients. Ann Oncol 1997, 8:973-978.

36. Thieblemont C, Coiffier B: Lymphoma in older patients. J Clin Oncol 2007, 25:1916-1923.

37. Zucca E, Roggero E, Bertoni F, Cavalli F: Primary extranodal non-Hodgkin's lymphomas. Part 1: Gastrointestinal, cutaneous and genitourinary lymphomas. Ann Oncol 1997, 8:727-737.

38. Zucca E, Roggero E, Bertoni F, Conconi A, Cavalli F: Primary extranodal non-Hodgkin's lymphomas. Part 2: Head and neck, central nervous system and other less common sites. Ann Oncol 1999, 10:1023-1033.

39. Cavalli F, Stein H, Zucca E: Extranodal Lymphomas: Pathology and Management London: Informa Healthcare; 2008.

40. Krol ADG, le Cessie S, Snijder S, Kluin-Nelemans JC, Kluin PM, Noordijk EM: Primary extranodal non-Hodgkin's lymphoma (NHL): the impact of alternative definitions tested in the Comprehensive Cancer Centre West population-based NHL registry. Ann Oncol 2003, 14:131-139.

41. Fujita A, Tomita N, Fujita H, Motohashi K, Hyo R, Yamazaki E, Hattori M, Fujisawa S, Kanamori H, Ogawa K, et al: Features of primary extranodal lymphoma in Kanagawa, a human T-cell leukemia virus type 1 nonendemic area in Japan. Med Oncol 2009, 26:49-54.

42. Lal A, Bhurgri Y, Vaziri I, Rizvi NB, Sadaf A, Sartajuddin S, Islam M, Kumar P, Adil S, Kakepoto GN, et al: Extranodal non-Hodgkin's lymphomas-a retrospective review of clinico-pathologic features and outcomes in comparison with nodal non-Hodgkin's lymphomas. Asian Pac J Cancer Prev 2008, 9:453-458.

43. Temmim L, Baker H, Amanguno H, Madda JP, Sinowatz F: Clinicopathological Features of Extranodal Lymphomas: Kuwait Experience. Oncology 2004, 67:382-389.

doi:10.1186/1746-1596-6-77

Cite this article as: Yang et al:: Subtype distribution of lymphomas in Southwest China: Analysis of 6,382 cases using WHO classification in a single institution. Diagnostic Pathology 2011 6:77.

\section{Submit your next manuscript to BioMed Central and take full advantage of:}

- Convenient online submission

- Thorough peer review

- No space constraints or color figure charges

- Immediate publication on acceptance

- Inclusion in PubMed, CAS, Scopus and Google Scholar

- Research which is freely available for redistribution

Submit your manuscript at www.biomedcentral.com/submit
Biomed Central 